\title{
Preliminary Results of Cord Blood Mononuclear Cell Therapy for Multiple System Atrophy: A Report of Three Cases
}

\author{
Shu-Hui Wu ${ }^{a}$ Hai-Xin Yang ${ }^{a}$ Gui-Hua Jiang ${ }^{b}$ Dian-Rong Gong ${ }^{a}$ \\ Le-Xin Wang ${ }^{c}$

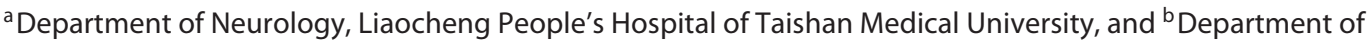 \\ Laboratory Medicine, Guanxian People's Hospital, Liaocheng, PR China; ' $S$ School of Biomedical Sciences, \\ Charles Sturt University, Wagga Wagga, N.S.W., Australia
}

\section{Key Words}

Cord blood mononuclear cell · Transplantation · Multiple system atrophy

\section{Abstract}

Objectives: This study was designed to evaluate the effects of cord blood mononuclear cell transplantation in multiple system atrophy (MSA). Clinical Presentation and Intervention: Cord blood mononuclear cells $\left(1-2 \times 10^{8}\right.$ cells $\left./ 6 \mathrm{ml}\right)$ were injected into the subarachnoid space using lumbar puncture in patients 1 and 2 and cisterna magna puncture in patient 3 in the 3 patients with MSA. The cord blood mononuclear cell transplantation was repeated 30 days after the first treatment in patients 1 and 2; it was repeated twice in patient 3 . The clinical outcomes of treatment were used to assess the Unified Multiple System Atrophy Rating Scale (UMSARS) before, 90 and 180 days after the cell transplantation. There were no clinically noticeable side effects from the cord blood mononuclear cells. The UMSARS scores improved after 90 days of the cord blood mononuclear cell therapy in all 3 patients, the most significant improvement being that in urinary incontinence and ability to walk. Con-

\begin{tabular}{ll}
\hline KARGER & $\begin{array}{l}\text { ( } 2013 \text { S. Karger AG, Basel } \\
1011-7571 / 13 / 0233-0282 \$ 38.00 / 0\end{array}$ \\
E-Mail karger@karger.com & $\begin{array}{l}\text { This is an Open Access article licensed under the terms of the } \\
\text { www.karger.com/mpp }\end{array}$ \\
$\begin{array}{l}\text { Creative Commons Attribution-NonCommercial 3.0 Un- } \\
\text { ported license (CC BY-NC) (www.karger.com/OA-license), } \\
\text { applicable to the online version of the article only. Distribu- } \\
\text { tion permitted for non-commercial purposes only. }\end{array}$
\end{tabular}

clusions: Cord blood mononuclear cell transplantation was safe and potentially effective in the treatment of MSA in the 3 patients.

(c) 2013 S. Karger AG, Basel

\section{Introduction}

Multiple system atrophy (MSA) is a sporadic, progressive neurodegenerative disease involving extrapyramidal or pyramidal systems, the cerebellum and autonomic nervous system [1]. It is characterized clinically by varying degrees of parkinsonian features, cerebellar, autonomic, and urogenital dysfunction, and corticospinal disorders [1-3]. The MSA is mainly caused by cell loss in the striatonigral and olivopontocerebellar structures of the brain and spinal cord. The current management of MSA is predominantly supportive, and there is no curative treatment for it at this point in time.

Umbilical cord blood stem cells are undifferentiated cells that have abilities for self-renewal and multilineage differentiation. These cells have an intricate control system to prevent proteins from being wrongly structured 
and aggregated [4], and can make wrongly structured proteins to be degraded by ubiquitin proteasome and phagolysosome systems, thereby preventing disease progression [5]. Also, stem cells can be positioned around the lesions to differentiate into neurons and repair the damaged nerve tissues, so that patients are capable of restoring lost nerve function [6]. Cord blood stem cells can differentiate into neurons under suitable conditions [7]. Previous studies have shown that subarachnoid implantation of stem cells through lumbar puncture is safe and has few side effects [8]. However, the safety of subarachnoid injection of cord mononuclear cells is unclear. In this report we describe the clinical outcomes of 3 patients who were treated with umbilical cord blood mononuclear cell transplantation.

\section{Case Reports}

This study was approved by our Institutional Review Board, and written informed consent was obtained from the patients. The clinical assessments of the 3 patients were performed by a neurologist (H.-X.Y.) who was blinded to the patient's treatments.

\section{Patient 1}

A 53-year-old woman was admitted on November 2, 2010, for progressively unsteady gait over the past 24 months, and slurred speech in the last 6 months. She had multiple falls due to the unsteady gait and leg weakness. She also began to have trouble in swallowing fluid including water, and developed urinary incontinence and postural hypotension in the last 6 months. She needed to go to the toilet to pass urine every $30-40 \mathrm{~min}$ and thereby completely losing control of the bladder had to wear pads. Her supine blood pressure (BP) was $140 / 90 \mathrm{~mm} \mathrm{Hg}$ and her standing BP was 70/35 mm Hg. Physical examination showed that her respiratory and cardiovascular functions were normal. Cranial nerves were intact. Muscle strength in the 4 limbs was at grade 5 with increased lower limb muscle tension, and positive bilateral Hoffmann's sign. There was tendon hyperreflexia in both lower extremities. Sensation to pain and light touch was normal in the limbs, but she was unable to perform the finger-nose test or heel-knee-tibia test. Romberg's sign was positive and she could not walk in a straight line. Brain magnetic resonance imaging (MRI) showed cerebellar atrophy. The Unified Multiple System Atrophy Rating Scale (UMSARS) part I [2] score was 21, the UMSARS part II score was 26, with a total score of 47 .

\section{Patient 2}

A 57-year-old man was admitted on February 23, 2010, because of unsteady gait accompanied by dizziness of 3 years, which had worsened in the last 2 months. He also had urinary urgency, going to the toilet every $40 \mathrm{~min}$ during the day and every $1-2 \mathrm{~h}$ at night, and subsequently became incontinent which did not respond to medical therapy. A month before admission he had been unable to stand up due to leg muscle weakness. On examination he had postural hypotension, with a supine $\mathrm{BP}$ of $130 / 80 \mathrm{~mm} \mathrm{Hg}$ and a stand- ing $\mathrm{BP}$ of $80 / 50 \mathrm{~mm} \mathrm{Hg}$. Muscle strength was at grade 5 in the 4 limbs with an increased muscle tension in the lower limbs. He had a positive Romberg's sign and a positive bilateral heel-knee-tibia test. Brain MRI showed lacunar infarction and cerebellar atrophy. His UMSARS part I score was 18, the UMSARS part II score 23.

\section{Patient 3}

A 58-year-old woman was admitted on July 13, 2010, for progressive unsteady gait of 3 years. She also developed speech difficulties with deterioration of verbal fluency. In recent months she had begun to experience swallowing difficulties, urinary frequency (going to the toilet every $30 \mathrm{~min}$ during the day and hourly during the night), urgency and incontinence. Three days before admission, she had not been able to walk unaided. On physical examination she had slurred speech, and reduced lower extremity muscle strength (grade 4). The muscle tension was high in the lower limbs. Bilateral heel-knee-tibia test and Romberg's sign were positive. Brain MRI showed multiple cerebral infarction and malacia formation, cerebellum and brain stem atrophy. The UMSARS part I score was 26, and the UMSARS part II score 36.

\section{Stem Cell Transplantation}

The umbilical cord blood was donated by volunteers following natural childbirth at our Obstetrics Wards. The blood was screened for hepatitis and HIV. Under sterile conditions, mononuclear cells were isolated and purified from cord blood by using bone marrow and cord blood nuclear cell isolation reagent kits (Wealthlin Science and Technology Inc., Vancouver, Canada), as per the manufacturer's instructions. The isolated cells $\left(1-2 \times 10^{8}\right.$ cells) were subsequently resuspended in $6 \mathrm{ml}$ physiological saline. The resuspended mononuclear cells were slowly injected into the subarachnoid space using lumbar puncture in patients 1 and 2, and/or cisterna magna puncture in patients 2 and 3 . This treatment was repeated 3 times in patient 1 , and once in patients 2 and 3 , with a 4 -week interval between the two treatments. The patients were followed up in our Outpatient Clinics at 3 and 6 months after completion of the last cord blood mononuclear cell transplantation.

\section{Results}

None of the patients had clinically noticeable side effects, such as fever or rash. Patient 3 had several days of hiccups which resolved spontaneously without any specific treatment. There were no significant changes in full blood count, blood biochemistry profile, renal or liver function after the treatment. The most noticeable clinical changes in all 3 patients were improvement in the ability to walk, and the alleviation of urinary urgency or incontinence, which resolved in all patients. Improvement in the UMSARS scores were noticed 3 months after the therapy in patient 1 and further improvement in the scores was found 6 months after treatment (table 1). The UMSARS scores in patients 2 and 3 also improved 3 and 6 months after the therapy (table 1). 
Table 1. The UMSARS scores

\begin{tabular}{|c|c|c|c|c|c|c|c|c|c|}
\hline \multirow[t]{2}{*}{ Scale } & \multicolumn{3}{|l|}{ Patient 1} & \multicolumn{3}{|l|}{ Patient 2} & \multicolumn{3}{|l|}{ Patient 3} \\
\hline & baseline & $\begin{array}{l}\text { at } \\
3 \text { months }\end{array}$ & $\begin{array}{l}\text { at } \\
6 \text { months }\end{array}$ & baseline & $\begin{array}{l}\text { at } \\
3 \text { months }\end{array}$ & $\begin{array}{l}\text { at } \\
6 \text { months }\end{array}$ & baseline & $\begin{array}{l}\text { at } \\
3 \text { months }\end{array}$ & $\begin{array}{l}\text { at } \\
6 \text { months }\end{array}$ \\
\hline Speech & 2 & 1 & 1 & 0 & 0 & 0 & 2 & 1 & 1 \\
\hline Swallowing & 2 & 2 & 1 & 1 & 0 & 0 & 2 & 1 & 0 \\
\hline Hand writing & 1 & 1 & 1 & 1 & 1 & 1 & 1 & 1 & 1 \\
\hline Dressing & 1 & 0 & 0 & 2 & 1 & 1 & 2 & 2 & 1 \\
\hline Hygiene & 1 & 0 & 0 & 1 & 0 & 0 & 2 & 2 & 1 \\
\hline Walking & 2 & 2 & 1 & 2 & 1 & 1 & 3 & 2 & 2 \\
\hline Falling & 2 & 1 & 1 & 2 & 1 & 1 & 3 & 2 & 2 \\
\hline Orthostatic symptoms & 3 & 2 & 1 & 3 & 1 & 1 & 3 & 2 & 2 \\
\hline UMSARS part II & 26 & 18 & 12 & 23 & 9 & 9 & 36 & 27 & 24 \\
\hline UMSARS & 47 & 31 & 21 & 41 & 17 & 16 & 62 & 45 & 39 \\
\hline
\end{tabular}

\section{Discussion}

In this study, the 3 patients with MSA treated with cord blood mononuclear cell transplantation improved the UMSARS scores and the neurological deficiencies 3 months after the treatment. The lumbar puncture and cisterna magna puncture techniques used to deliver the blood mononuclear cells did not show any procedurerelated side effects or complications.

Gilman et al. [1] proposed 4 sets of clinical features and diagnostic criteria for MSA. These are autonomic nerve dysfunction or urine voiding dysfunction, Parkinson-like symptoms, cerebellar ataxia and cone system dysfunction. The diagnosis of our 3 patients was largely clinical and based on the classical symptoms of MSA [1]. It was supported by brain MRI showing cerebellar or brain stem atrophy. The MSA symptoms in our patients began insidiously, slowly progressed and eventually became multiple sets of clinical features resulting in a loss of full or partial abilities for independent living [3]. Autologous mesenchymal stem cells have also been used to treat MSA. In a recent randomized trial where mesenchymal stem cells were administered either intra-arterially or intravenously, a small increase in the total and part II UMSARS scores was recorded as compared with the placebo group [9]. To date, the optimal forms of stem cells (mesenchy- mal stem cells or cord blood mononuclear cells) and the best routes of stem cell delivery (intravascular or direct central nervous system injection) are unclear. In the present study, cord blood mononuclear cells were injected into the subarachnoid space using lumbar puncture or cisterna magna puncture. These direct delivery techniques appear to be safe and effective in the 3 patients, as no major complications were observed and the UMSARS scores were improved 6 months after the treatment.

A major limitation of the present report was the small number of patients and there was no control for comparison and brain MRI was not done after treatment. Randomized and placebo-controlled trials are required in a large patient population to ascertain the clinical effect of cord blood mononuclear cell therapy on MSA.

\section{Conclusion}

The direct injection of cord blood mononuclear cells into the subarachnoid space seemed safe in these patients. This mononuclear cell therapy appeared effective in alleviating the neurological symptoms in our patients with MSA. 


\section{References}

$>1$ Gilman S, Wenning GK, Low PA, et al: Second consensus statement on the diagnosis of multiple system atrophy. Neurology 2008;71: 670-676.

$>2$ Wenning GK, Tison F, Seppi K, et al: Development and validation of the Unified Multiple System Atrophy Rating Scale (UMSARS). Mov Disord 2004;19:1391-1402.

-3 Jellinger KA, Seppi K, Wenning GK: Grading of neuropathology in multiple system atrophy: proposal for a novel scale. Mov Disord 2005;20(suppl 12):S29-S36.
4 Kan I, Melamed E, Offen D: Autotransplantation of bone marrow-derived stem cells as a therapy for neurodegenerative diseases. Handb Exp Pharmacol 2007;180:219-242.

$>5$ Colosimo C, Tiple D, Wenning GK: Management of multiple system atrophy: state of the art. J Neural Transm 2005;112:1695-1704.

-6 Crigler L, Robey RC, Asawachaicham A, et al: Human mesenchymal stem cell subpopulations express a variety of neuro-regulatory molecules and promote neuronal cell survival and neuritogenesis. Exp Neurol 2006;198:5464.
7 Cho JW, Kim SY, Park SS, et al: The G2019S LRRK2 mutation is rare in Korean patients with Parkinson's disease and multiple system atrophy. J Clin Neurol 2009;5:29-32.

$\rightarrow 8$ Tian C, Wang X, Wang X, et al: Autologous bone marrow mesenchymal stem cell therapy in the subacute stage of traumatic brain injury by lumbar puncture. Exp Clin Transplant 2013;11:176-181.

9 Lee PH, Lee JE, Kim HS, et al: A randomized trial of mesenchymal stem cells in multiple system atrophy. Ann Neurol 2012;72:32-40. 